- Enhance diversity within LOROS

- Increase the knowledge of and respect for the charity within the community

- Creation of 'Volunteer Voice': a support group that has membership from the senior management team and volunteers.

Volunteering was categorised into different areas/services e. g. clinical, snack bar, fundraising, shops. Role descriptions for each area were created. This enabled:

- Clear expectations for each role

- Identification of training requirements

- Additional support and clinical training for those directly supporting patients on the ward and within home visiting.

- Looking at other specialist roles for volunteer.

Data Management ensured correct volunteer details, benefits included:

- GDPR compliance

- Progression of training

- Improve communication

- Better reporting mechanisms to Management

- Efficient rota

- Effective governance.

Volunteering within LOROS sits within the strategic aims of the organisation in order to support its service offer and financial sustainability. Whilst maintaining a positive reputation with an associated high public profile, volunteering continues to grow: we now have 1481 volunteers (increased by over 300 in one year). Volunteering is also working on a number of initiatives transforming palliative care into the community:

- Telephone be-friending service

- LOROS Local, a mobile resources in the community [See abstract \#164]

- Supporting LOROS@ home service.

With all of the above now in place we have a sustainable volunteering model for the hospice.

\section{P-277 PALLIATIVE CARE VOLUNTEERS IN EUROPE: QUALITATIVE ANALYSIS OF VOLUNTEER ACTIVITIES AND EXPERIENCES}

${ }^{1}$ Ros Scott, ${ }^{2}$ Anne Goossensen, ${ }^{3}$ Sheila Payne, ${ }^{4}$ Mag Leena Pelttari. ${ }^{1}$ University of Dundee, Dundee, UK; ${ }^{2}$ University of Humanistic Studies, Utrecht, Netherlands; ${ }^{3}$ Lancaster University, Lancaster, UK; ${ }^{4}$ Hospice Austria, Vienna, Austria

\subsection{6/bmjspcare-2018-hospiceabs.302}

Background Volunteers are an essential and integral part of hospice and palliative care (HPC) in many countries. It is often others, rather than volunteers, who report their activities and experiences. Led by the European Association for Palliative Care (EAPC) Task Force in Volunteering, this project aimed to give volunteers a voice and to invite their personal stories of involvement in HPC in their own words.

Aims The aims were to understand: the experiences of volunteers in HPC; why they work in HPC; what volunteering in this field means to them.

Method Task Force members in seven countries were asked to invite five volunteers to write about their volunteering activities and experiences in their own language. Two prompt questions were given to volunteers: 'What do you do as a volunteer?' and 'What does it mean to you?' Stories were translated into English and a qualitative framework used for analysis.

Results

- In total, 37 stories of 400-500 words were received from eight countries.

- Almost all $(n=34)$ volunteers offered practical, emotional, social and spiritual support to adult patients and families.

- 32 were involved in diverse adult HPC settings including patients' homes, hospices, hospitals and care homes and two in community children's palliative care

- All found significant meaning in HPC volunteering, described as an important part of their life and values

- Volunteers described the privilege of being with people at end of life and how much they learn from encounters with death and dying.

- Others highlighted the challenges of HPC volunteering and how their lives are enhanced by their experience.

Conclusion The narratives gave an insight into the personal stories of volunteers in different countries and highlighted many similarities in shared experiences and values. Understanding these perspectives can help HPC organisations to improve how volunteers skills may best be utilised and supported.

\section{P-278 USING A PRACTICE DEVELOPMENT APPROACH TO DEVELOP A NEW ROLE FOR VOLUNTEERS IN A HOSPICE}

Karen Filsell, Irene Barday, Tommy Dalgleish, Nicola Mackay, Dot Partington. St Columba's Hospice, Edinburgh, UK

\subsection{6/bmjspcare-2018-hospiceabs.303}

Background Staff on our Inpatient Unit (IPU) are keen to enhance the experience of patients and families. Our Volunteer Services Team wants to broaden the ways in which volunteers contribute their skills and experience. The IPU staff worked with the Volunteer Services Team on a new role for volunteers on the wards.

Aim To develop a new role for Inpatient Unit volunteers which is fully integrated into the staff team.

Method A practice development approach (collaboration, inclusion and participation) was used, drawn from the nine principles of Practice Development (McCormack, Manley, \& Titchen, 2013) and the Person-Centred Practice Framework (McCance \& McCormack, 2017).

Pre-preparation:

- Literature review

- Consultation with other hospices about their practice

- Staff, volunteers, patients and families participated in a range of consultations. Four questions were asked: What do volunteers bring to the ward? What else could they do? What training do they need? What support do they need?

- A small development team was identified to manage the project

- The project was promoted internally to maintain staff/ volunteer engagement

- An educational programme for two Volunteers, Charge Nurses and Volunteer Champions (Health Care Assistants). 